International Journal of Latest Trends in Engineering and Technology

Vol.(7)Issue(3), pp. 069-076

DOI: http://dx.doi.org/10.21172/1.73.510

e-ISSN:2278-621X

\title{
Computational study on stress \& deflections of Glass Epoxy Composites
}

\author{
T. Prasad ${ }^{1}$, R. Naresh Kumar Goud ${ }^{2}$, P.Chinna Sreenivas Rao ${ }^{3}$ and K. Srinivasa Chalapati ${ }^{4}$
}

\begin{abstract}
Composites find their applications in many fields. One of the major being the air craft Industry where it is used for the manufacture of the radomes. The manufacturing of the E-glass epoxy composite in the laminate form involves the design of the mould and the manufacturing of a composite laminate using the 8mould. The laminate is manufactured by table tap pre-preg method manually and then subjected to a compressive load for thorough distribution of resin in respective lamina and then finally subjected to curing by gradual heating towards high temperature in a closed control thermal oven. Then test the manufactured laminate for its tensile strength and Young's modulus.

These days lot of research is directed to understand the fatigue failure behavior of laminated composites. The materials usage is increasing in all sorts of engineering applications due to high specific strength and stiffness. Fibre reinforced composite materials are selected for weight critical applications and these materials have good rating as per the fatigue is concerned. Composite materials are anisotropic in mature and their failure behaviour is different from that of isotropic materials. Tensile tests were performed and balanced symmetric laminates of $( \pm 0) 8,( \pm 20) 8,( \pm$ $30) 8$, $( \pm 40) 8,( \pm 45) 8,( \pm 55) 8,( \pm 60) 8$ Degree orientation. The tensile test were performed on the laminated in CIPET, Hyderabad laboratories and Saint Gobain Vetrotex India Private Ltd., The aim of the paper is the deflection to be induced in the specimen is estimated by conducting the deflection tests on the specimens of laminates $( \pm 0) 8,( \pm 20) 8,( \pm 30) 8,( \pm 40) 8,( \pm 45) 8,( \pm 55) 8,( \pm 60) 8$.
\end{abstract}

\section{INTRODUCTION}

Composite are gaining wider acceptance for use on board warships and submarines due to number of advantages viz. high strength to weight ratio, ability to be molded into complex shapes, better EMI performance, absence of corrosion palliatives which otherwise are source for electronic and magnetic signature. Composite materials made from E-Glass fibers and epoxy resins have become very popular as a radome material due to its outstanding transparency to microwave and having good mechanical properties.

$>$ The increasing popularity of the material for underwater application are posing great difficulties to the designer to select right combination of composition $\&$ shape of radome due to the complex nature of the structure and the loading conditions for the useful operation life.

${ }^{1}$ Anurag Group of Institutions, Hyderabad, India.

${ }^{2}$ Anurag Group of Institutions, Hyderabad, India.

${ }^{3}$ Anurag Group of Institutions, Hyderabad, India.

${ }^{4}$ Anurag Group of Institutions, Hyderabad, India. 
Mechanical properties of composite materials are influenced by several process etc. Conducting the tests on standard specimens and evaluating mechanical properties is the most important aspect in design of composite material applications. The micro-mechanics and failure mechanism of composite material is very complex compared to the conventional isotropic materials. Depending on the reinforcement, composition content \& its percentage, appropriate theory \& failure mechanism can be considered for designing the radome made of E-Glass epoxy composite.

The word composite - means consisting of two or more distinct parts. Thus a material has two or more chemically distinct constituents or phases, on a macro scale, having a distinct interface separating them, may be considered a composite material. Only when the constituent phases have significantly different physical properties and thus the composite properties are noticeably different from the constituent properties that we have come to recognize these materials as composites. Modern structural composites, frequently referred to as Advanced Composites are a blend of two or more components, one of which is made up of stiff, long fibers, and the other, a binder or matrix which holds the fibers in place. The fibers are strong and stiff relative to the matrix and are generally orthotropic (having different properties in two different directions). The fiber, for advanced structural composites, is long, with aspect ratio (length to diameter ratios) of over 100 .

\section{Methodology}

Any material in an elongated form such that it has very high length to diameter ratio is called a fiber. Fibers are much stiffer and stronger than the same material in bulk form. Materials have actual strengths which are several magnitudes lower than the theoretical strengths. This difference is due to the inherent flaws in the material. As the fibers become smaller in diameter, it reduces the chances of an inherent flaw in the material, thereby the strength is increased. The different types of fibers are,

\section{a) GLASS FIBERS}

These fibers graded as E, A, C, S, Z, M \& D.

'E' glass is electrical grade which is having high bulk electrical resistivity and high surface resistivity.

'A' glass in one which is having high alkali content and of very limited use.

' $\mathrm{C}$ ' glass is a chemical quality and used for corrosion resistance to acids.

' $\mathrm{S}$ ' glass has higher strength and elastic modulus than E glass.

' $\mathrm{Z}$ ' glass is used to reinforce the cement products.

'M' glass has high value of young's modulus but specific strength is low.

' $\mathrm{D}$ ' glass has low dielectric loss value and hence is specifically suited for high performance electronic applications radomes etc.

The various forms of glass fiber reinforcement are as continuous stand and roving, chopped stands, yarns, mats etc. Ingredients such as sand, limestone, and alumina are dry mixed and melted in a refractory furnace. The temperature of the melt is generally around $1260^{\circ} \mathrm{C}$. In a 
direct melt process, the molten glass is introduced into platinum bushing, where the molten glass is gravity fed through a multiplicity of holes in the base of the bushing.

\section{b) CARBON AND GRAPHITE FIBERS}

Strictly speaking, the term "graphite" fibers is a misnomer since there is no true graphite crystal structure in the fibers. The term 'graphite fiber' is used to describe fibers that have a carbon content in excess of $99 \%$ whereas the term "carbon fiber" describes fibers it have a carbon content of $8095 \%$. The carbon content is a function of the heat treatment temperature.

\section{c) ARAMID FIBERS}

Aramid fiber is a generic term for a specific type of 'aromatic polyamide fiber'. It is also defined as a manufactured fiber in which the fiber forming substance is a long chain synthetic polyamide in which at least $85 \%$ of the amide linkages are attached directly to two atomatic rings, compared to nylons and other conventional polyamides since the latter polymers contain few if any aromatic groups in the main chain of the polymer.

\section{RESULTS AND DISCUSSIONS:}

Tensile tests were performed on balanced symmetric laminates of $( \pm 0)_{8},( \pm 20)_{8},( \pm 30)_{8},( \pm 40)_{8},( \pm$ $45)_{8},( \pm 55)_{8},( \pm 60)_{8}$ degree orientation. The tensile test were performed on the laminates which are made as per the ASTM D-638 specifications.

The test was performed in the CIPET, Hyderabad laboratories and saint GOBAIN VETROTEX India private Ltd. Quality control laboratories, Hyderabad and DRDL Hyderabad laboratory. The consolidated test results are furnished in table No. 5.1.

\begin{tabular}{|c|c|c|}
\hline $\begin{array}{c}\text { Sample orientation sequence in deg } \\
\text { (CROSSPLY) with eight layers }\end{array}$ & $\begin{array}{c}\text { Max Tensile strength } \\
\text { in (MPa) }\end{array}$ & $\begin{array}{c}\text { Modulus at } \\
\text { 0.50\% Strain } \\
\text { in(GPa) }\end{array}$ \\
\hline$\left[ \pm \mathbf{0}^{\mathbf{0}}\right]_{8}$ & 358 & 37.96 \\
\hline$\left[ \pm \mathbf{2 0}^{\mathbf{0}}\right]_{8}$ & 288 & $\mathbf{3 0 . 2 2}$ \\
\hline$\left[ \pm \mathbf{3 0}^{\mathbf{0}}\right]_{8}$ & 170 & 18.9 \\
\hline$\left[ \pm \mathbf{4 0}^{\mathbf{0}}\right]_{8}$ & 162 & 10.21 \\
\hline$\left[ \pm 45^{0}\right]_{8}$ & 65 & 10.54 \\
\hline$\left[ \pm 55^{\circ}\right]_{8}$ & 74.3 & 10.89 \\
\hline$\left[ \pm \mathbf{6 0}^{\mathbf{0}}\right]_{8}$ & 113. & 10.86 \\
\hline
\end{tabular}

Table No:5.1 Tensile Result Analysis 


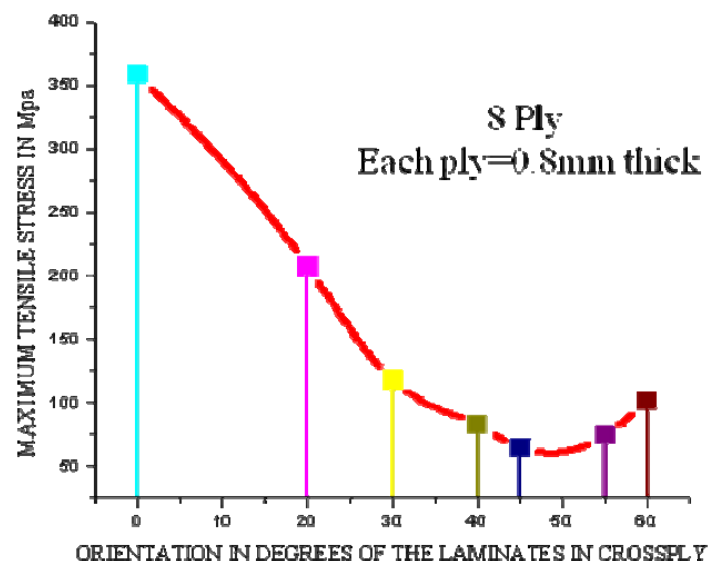

\subsubsection{Experimental Setup for Deflection test:}

The deflection to be induced in the specimen is estimated by conducting the deflection tests on the specimens of laminates $\left.[ \pm 0]_{8},[ \pm 20]_{8},[ \pm 30]_{8},[ \pm 40]_{8,}, \pm 45\right]_{8},[ \pm 55]_{8}$ and $[ \pm 60]_{8}$. The photograph of the experimental setup is shown in Fig. No. 5.2 and the schematic diagram is shown in the Fig.No.5.3.The experimental set up is instrumental in estimating the deflection to be induced to simulate the required bending stress in the specimen subjected to flexural bending .

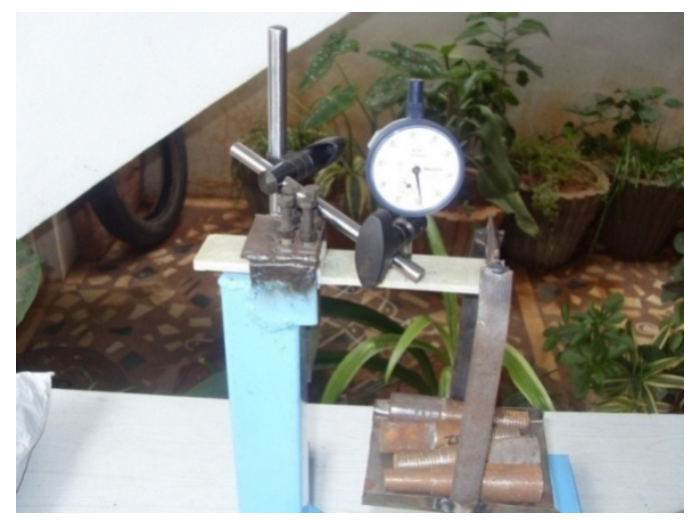

Fig. No. 5.2 Experimental setup for deflection test

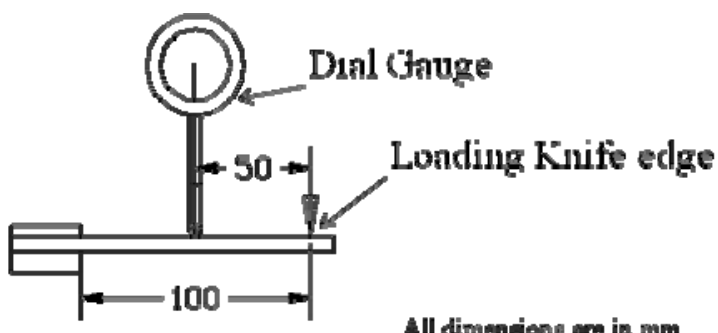

Fig. No. 5.3. Schematic representation of deflection experimental set up 
Making use of the Experimental setup, deflection test is performed on the $[ \pm 0]_{8},[ \pm 20]_{8},[ \pm 30]_{8},[ \pm 40]_{8},[$ $\pm 45]_{8},[ \pm 55]_{8}$ and $[ \pm 60]_{8}$ specimens. As the total load could not be simulated on deflection test due to experimental setups' geometrical constraints, the experimental results were extrapolated to estimate actual deflection. This is done origin lab software. The deflection test results and estimated deflection are furnished in the following sections 5.5.1 (a) to (g) on the specimens. The specifications of these specimens are furnished in the table No. 5.2.

Table no. 5.2 Specification with respect to the orientation of stacking.

\subsection{1 (a) Deflection test on $[ \pm 0]_{8}$}

\begin{tabular}{|c|c|c|c|c|}
\hline $\begin{array}{c}\text { S.No } \\
\text { of } \\
\text { Test }\end{array}$ & $\begin{array}{c}\text { Sample } \\
\text { orientation } \\
\text { sequence in } \\
\text { deg } \\
(\text { CROSSPLY) }\end{array}$ & $\begin{array}{c}\text { effective } \\
\text { length of } \\
\text { specimen } \\
\text { in mm. }\end{array}$ & $\begin{array}{c}\text { thickness } \\
\text { of } \\
\text { specimen } \\
\text { in mm }\end{array}$ & $\begin{array}{c}\text { number } \\
\text { of } \\
\text { layers }\end{array}$ \\
\hline $\mathrm{a}$ & {$\left[ \pm 0^{0}\right]$} & $100 \mathrm{~mm}$ & $5.85 \mathrm{~mm}$ & 8 \\
\hline $\mathrm{b}$ & {$\left[ \pm 20^{0}\right]$} & $100 \mathrm{~mm}$ & $5.85 \mathrm{~mm}$ & 8 \\
\hline $\mathrm{c}$ & {$\left[ \pm 30^{0}\right]$} & $100 \mathrm{~mm}$ & $5.85 \mathrm{~mm}$ & 8 \\
\hline $\mathrm{d}$ & {$\left[ \pm 40^{0}\right]$} & $100 \mathrm{~mm}$ & $5.85 \mathrm{~mm}$ & 8 \\
\hline $\mathrm{e}$ & {$\left[ \pm 45^{0}\right]$} & $100 \mathrm{~mm}$ & $5.85 \mathrm{~mm}$ & 8 \\
\hline $\mathrm{f}$ & {$\left[ \pm 55^{0}\right]$} & $100 \mathrm{~mm}$ & $5.85 \mathrm{~mm}$ & 8 \\
\hline $\mathrm{g}$ & {$\left[ \pm 60^{0}\right]$} & $100 \mathrm{~mm}$ & $5.85 \mathrm{~mm}$ & 8 \\
\hline
\end{tabular}

Table no 5.3 Load versus Deflection experimental data of $\left[ \pm 0^{0}\right]_{8}$ specimen

\begin{tabular}{|r|r|}
\hline $\begin{array}{r}\text { Load In } \\
\text { Newton }\end{array}$ & $\begin{array}{r}\text { Deflection } \\
\text { in } \mathrm{mm}\end{array}$ \\
\hline 0 & 0 \\
\hline 3.65 & 0.06 \\
\hline 7.46 & 0.12 \\
\hline 10.86 & 0.2 \\
\hline 14.34 & 0.28 \\
\hline 17.6 & 0.38 \\
\hline 20.35 & 0.46 \\
\hline 23.66 & 0.56 \\
\hline 26.5 & 0.66 \\
\hline 29.25 & 0.8 \\
\hline 32.07 & 0.9 \\
\hline 35.53 & 1.08 \\
\hline
\end{tabular}




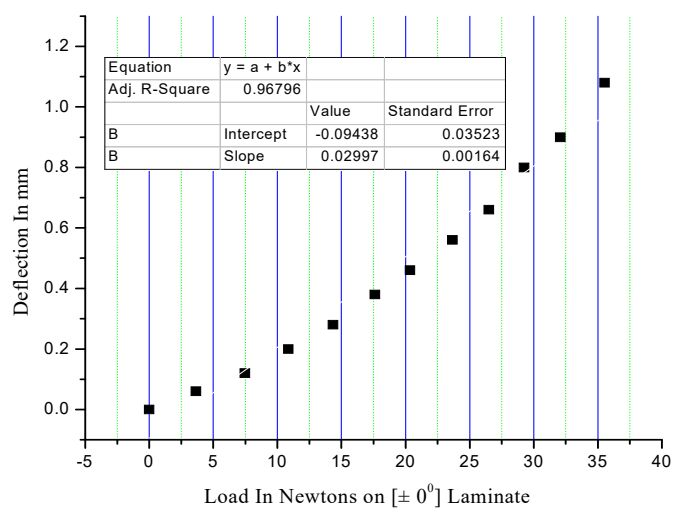

Fig. no 5.4 Load versus deflection curve of cantilever beam for $\left[ \pm 0^{0}\right]$ Balanced symmetric laminate

The deflection behaviour is almost linear, the equation of the fitted line is

$$
\mathrm{y}=.02997 \mathrm{x}-0.09438
$$

From this equation the approximate deflection ' $y$ ' to be induced to simulate bending load ' $x$ ' of 320 Newton is given by,

$$
y=320 * .02997-0.09438
$$

Then ' $y$ ' (Deflection) $=9.5 \mathrm{~mm}$

The eccentricity given at the hinge, $\delta=x * 2.1 \mathrm{~mm}$

$$
\begin{aligned}
& =9.5 * 2.1 \mathrm{~mm} \\
= & 20 \mathrm{~mm}
\end{aligned}
$$

\subsection{1 (b) Deflection test on $\left[ \pm 20^{0}\right]_{8}$ specimen:}

\begin{tabular}{|r|r|}
\hline $\begin{array}{r}\text { Load In } \\
\text { Newton }\end{array}$ & $\begin{array}{r}\text { Deflection } \\
\text { In mm }\end{array}$ \\
\hline 0 & 0 \\
\hline 3.65 & 0.1 \\
\hline 6.49 & 0.16 \\
\hline 9.804 & 0.28 \\
\hline 13.284 & 0.4 \\
\hline 16.544 & 0.5 \\
\hline 20.004 & 0.62 \\
\hline 22.824 & 0.7 \\
\hline 25.574 & 0.8 \\
\hline 28.324 & 0.9 \\
\hline 31.144 & 1 \\
\hline 34.544 & 1.1 \\
\hline
\end{tabular}


Table no 5.4 Load versus Deflection experimental data of $\left[ \pm 20^{0}\right]_{8}$ specimen

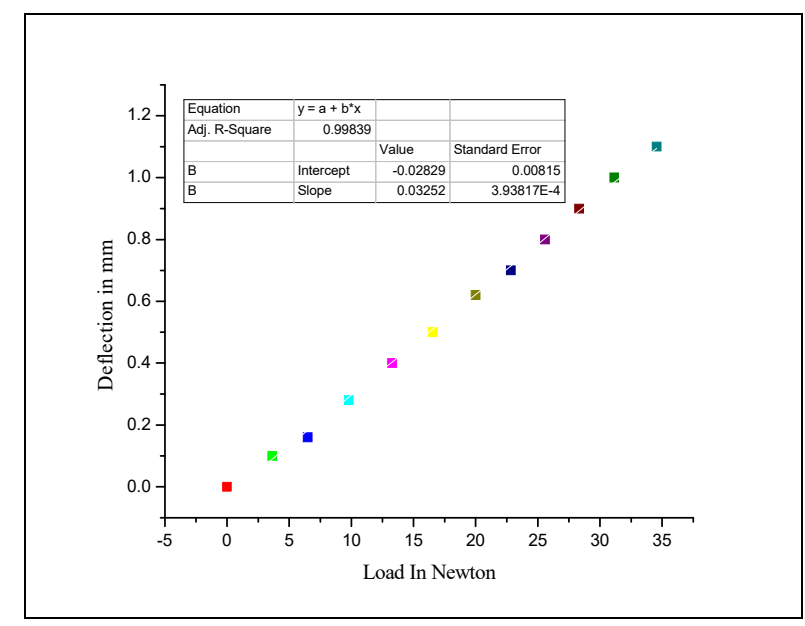

Fig. No 5.5 Load versus Deflection of $\left[ \pm 20^{0}\right]_{8}$ specimen

\section{CONCLUSIONS}

1) Tensile tests were performed on balanced symmetric laminates of $( \pm 0)_{8},( \pm 20)_{8},( \pm 30)_{8},( \pm 40)_{8}$, $( \pm 45)_{8},( \pm 55)_{8},( \pm 60)_{8}$ degree orientation. The maximum tensile occurs at $( \pm 0)_{8}$, orientation, minimum tensile stress at $( \pm 0)_{8}$.

2) Making use of experimental set up, deflection test is performed on the $( \pm 0)_{8},( \pm 20)_{8},( \pm$ $30)_{8},( \pm 40)_{8},( \pm 45)_{8},( \pm 55)_{8},( \pm 60)_{8}$ specimens. As the total load could not be simulated on deflection test due to experimental setups geometrical constraints, the experimental results were extrapolated to estimate actual deflection.

\section{REFERENCES}

1. Balram gupta, "Aerospace Materials" Vol. 1 to 5, S Chand and company.

2. "Aalysis and performance of fiber composites", Agarwal BD and Boutman LJ, John Wiley and sons.

3. "Mechanics of composite materials", Jones RM, Mcgraw Hill.

4. Titterton G, "Aircraft materials and process", 5 edition.

5. Greenhalgh RJS, Baynham E, Evans D, Canfer S, Robertson S, Morrow D, Temple S. Strength of epoxy-resin-based insulation systems in transverse tension and shear using two novel test pieces. International Journal of Adhesion \& Adhesives 2003;23(6):485-494.

6. Peter Ifju P, Myers D, Schulz W. Residual stress and thermal expansion of graphite epoxy laminates subjected to cryogenic temperatures. Composites Science and Technology 2006;66(14):2449-2455.

7. Saniee FF, Majzoobi GH, Bahrami M. An experimental study on the behavior ofglass-epoxy composite at low strain rates. Journal of Materials Processing Technology 2005;162-163(1):3945.

8. Ray BC. Thermal shock and thermal fatigue on delamination of glass fiber reinforced polymeric composites. Journal of Reinforced Plastics and Composites 2005;24(1):111-116. 
9. Cindy Foreman, "Advanced composites".

10. Lubin G, "Hand book of advanced plastics and fiber glass". 11. "Advanced composite materials", Lalit Gupta. 